RESEARCH ETHICS

\title{
Capacity, consent, and selection bias in a study of delirium
}

\author{
D Adamis, F C Martin, A Treloar, A J D Macdonald
}

J Med Ethics 2005;31:137-143. doi: 10.1136/jme.2002.000919

See end of article for authors' affiliations ....................

Correspondence to: Dr D Adamis, Academic Unit, Ladywell House, 330 Lewisham High Street, London SE13 6JZ, UK; dimaadamis@yahoo.com

Received 8 July 2002 Revised version received 23 November 2002 Accepted for publication 2 December 2003
Objectives: To investigate whether different methods of obtain
a study of delirium in older, medically ill hospital inpatients.

Design: Open randomised study.

Setting: Acute medical service for older people in an inner city teaching hospital.

Participants: Patients 70 years or older admitted to the unit within three days of hospital admission randomised into two groups.

Intervention: Attempted recruitment of subjects to a study of the natural history of delirium. This was done by either $(a)$ a formal test of capacity, followed by either a request for consent or an attempt at obtaining assent from a proxy, or (b) a combined informal capacity/consent process.

Main outcome measures: Prevalence and severity of delirium, and, as case mix measures, length of hospital stay and destination on discharge.

Results: Recruitment of subjects through establishing formal capacity and then informed consent was less successful (43.9\% $\vee 74 \%$ of those approached) and, compared with those recruited through the usual combined capacity/consent approach, yielded a sample with less cognitive impairment, lower severity of delirium, lower probability of case note diagnosis of delirium and lower rate of entering a care home.

Conclusions: Methods of obtaining informed consent may significantly influence the case mix of subjects recruited to a study of delirium. Stringent testing of capacity may exclude patients with delirium from studies, thus rendering findings less generalisable. A different method is necessary to achieve an ethical balance between respecting autonomy through obtaining adequate informed consent and avoiding sample bias.
$\mathrm{D}$ elirium is an acute, fluctuating disorder of attention and cognition, often associated with mood disturbances, especially fear and depression, as well as perplexity, difficulty thinking, delusions, and visual hallucinations. It is common and unpleasant and associated with delays in recovery and increased mortality from acute illness, worse functional outcome ${ }^{12}$ and increased healthcare costs. ${ }^{3}$ More than $20 \%$ of hospital medical inpatients over 70 years are likely to be delirious on admission, and the incidence rate per patient per admission is over $10 \%$, most of which occurs within the first few days. ${ }^{4}$ Predisposing and precipitating factors have been described ${ }^{5}$ and include pre-existing dementia, which increases the incidence fivefold. ${ }^{6}$

These adverse outcomes are associated with delirium even when baseline factors such as age, gender, dementia, APACHE II score, and premorbid functional measures are corrected for. ${ }^{2}$ Delirium may last for many months ${ }^{8}$ and longer term mortality and subsequent incidence of new onset dementia is several fold higher. ${ }^{9}$

The management of delirium at present consists of the treatment of the underlying medical condition, environmental manipulation, ${ }^{10}$ and perhaps symptomatic treatment if the patient is overactive, disturbed, or disturbing others. ${ }^{11}$ The irreversibility of some clinical features, ${ }^{12}$ the emerging evidence of a relation with dementia, ${ }^{13}$ and the poor prognosis independent of premorbid factors suggest that the pathophysiological processes causing the syndrome of delirium may also result in permanent decline of cerebral function. The strongest evidence is for disturbance of cholinergic neurotransmitter systems. ${ }^{14}$

Clinically, delirium has three clinical subtypes-hypoactive, hyperactive, and mixed-and there are differences in their outcomes, ${ }^{2}$ including the degree of reversibility. ${ }^{12}{ }^{15}$ It is not known whether these correlate with distinct cerebral pathological processes and therefore perhaps would respond to different therapeutic approaches. Studies linking clinical and pathological processes with outcomes are needed to investigate the relevance of this heterogeneity for therapeutic strategies.

As a preliminary stage, we investigated the feasibility of including a broad spectrum of delirious patients in such an observational study. In relation to its importance, the amount of published research on patients with delirium is small in comparison with equally common conditions. This is generally true of clinical research with older people. ${ }^{16}$ There are, however, particular ethical, clinical, and methodological difficulties of doing research with patients with delirium.

Even in non-invasive studies with minimal or low risk to the participating subjects, such as observational studies involving more than routine assessment, informed consent is required for the inclusion of patients if it can be obtained in a valid fashion. There has been more study concerning capacity to provide informed consent to medical treatment or investigation than consent for participation in clinical research, but the principles are the same, and have been clearly laid out in statements and guidance. ${ }^{17-19}$ The subject must be able to understand, retain, and believe the given information about the purpose, risks, benefits, and so on, and then deliberate, make, and communicate a decision.

Although significant cognitive impairment ${ }^{20}$ or psychiatric illness ${ }^{21}$ does not necessarily exclude the capacity to give valid informed consent, there is convincing evidence that clinicians are unreliable in assessing capacity and tend to overestimate the understanding of physically unwell patients, ${ }^{22}$ including those with delirium. ${ }^{23}$ Delirium is often missed clinically in the general hospital setting. ${ }^{24}$ Among patient groups such as older people with a hip fracture or acute medical illness, delirium is common, ${ }^{25}$ and it is likely that many of these patients lack valid capacity for a clinical consent decision. In this situation, local research ethics committees (LREC), at 
least in the UK, are guided by the World Medical Association Declaration of Helsinki (Ethical Principles for Medical Research Involving Human Subjects), initially adopted at its 18th General Assembly and subsequently amended, the latest version having been published in October $2000 .{ }^{26}$ Sentence 26 states: "Research on individuals from whom it is not possible to obtain consent, including proxy or advance consent, should be done only if the physical/mental condition that prevents obtaining informed consent is a necessary characteristic of the research population" and "consent to remain in the research should be obtained as soon as possible from the individual or a legally authorised surrogate". Most LRECs will regard proxy support for research concerning adults as constituting assent rather than consent. In English practice, legally authorised surrogates do not yet play a part.

The US National Bioethics Advisory Commission concluded that ethical involvement of individual subjects in research depends on one of the following three: informed consent of a subject with decisional capacity; prospective authorisation by the subject for their future participation in a particular class of research, given when the subject was still competent; or permission from a legally authorised representative chosen by the subject or from a concerned relative or friend who is available to monitor the subject's involvement in the research and base their decisions upon their best estimate of what the subject would have chosen if capable of making a decision. ${ }^{27}$

For research subjects who have or are liable to develop delirium, the following steps are therefore necessary. First, establishing if informed consent can be obtained with any validity necessitates deciding whether the potential subject has the capacity to consent. Capacity is specific to the issue at hand and, in ambiguous instances, the degree of certainty required about the judgement of capacity must be proportionate to the predicted risks of the proposed activities. Secondly, if capacity is present, informed consent may then be sought, or if capacity is not present, a suitable proxy must be identified and their assent sought. Although recognising that the latter has no legal basis and cannot replace consent, it does ensure that a proxy view is obtained which affords the opportunity for particular considerations about the patient to be made known to the researchers which might in turn lead them to decide against inclusion. Thirdly, the subject's consent for continuing participation must be sought if they recover capacity.

Sentence 19 of the Declaration of Helsinki states that: "Medical research is only justified [on human subjects] if there is a reasonable likelihood that the study populations in which the research is carried out stand to benefit from the results of the research". To satisfy this condition, researchers need to be able adequately to characterise their study population. If subjects whose mental state is both the subject of inquiry and the reason for lack of capacity are excluded from study, then knowledge cannot advance satisfactorily. In practice, however, people are excluded from published studies in significant numbers, which may therefore result in selection bias. ${ }^{28}$ The clearest way to minimise selective exclusion would be to assume incapacity for all potentially delirious subjects and seek LREC consent for inclusion in research of all potential subjects without their consent. This would clearly be unethical. A way needs to be found which balances the ethical needs to include as many patients with typical delirium on the one hand with the principles of autonomy and informed consent on the other.

We report here the feasibility and the consequences of a formal assessment of capacity as a prelude to obtaining consent to participate in a pilot study for the Natural History of Delirium study. This is a planned observational study of the relation between the severity and clinical characteristics of delirium, the severity of acute illness, and the pattern of recovery from delirium. We decided initially to use a structured assessment of capacity to consent to the pilot study (fig l) as this seemed to us to epitomise best practice in this assessment. However, we found that of the first 42 patients approached $15(36 \%)$ failed the formal test of capacity. This put the feasibility of the study in doubt and raised the question of whether such a strategy of formal capacity/consent would affect the case mix for inclusion in such a way as to introduce selection bias, with the important implication that the general applicability of our findings would be reduced.

To investigate case mix differences between selected groups of subjects, we chose features shown in previous work to influence both the likelihood and severity of delirium, such as pre-existing mental state, preadmission functional abilities, and severity of acute illness. Differences in these factors between groups of subjects included for study are likely to be associated with differences in incidence and severity of delirium in the group. Likewise, differences in outcome such as length of hospital stay and destination at hospital discharge are also influenced by the presence and severity of delirium in the group. ${ }^{2}$ Thus differences in these outcomes between groups also suggest case mix differences, likely in this population to include the presence or severity of delirium. Direct measures of mental state including cognition can also be used to compare the severity of delirium between groups.

\section{NULL HYPOTHESIS TESTED IN THIS STUDY}

In relation to delirium there is no difference in predisposing factors (age, Mini Mental State Examination (MMSE)), prevalence (as measured by CAM-see below), severity (as measured by DRS and RCDS-see below), and outcome (mortality and discharge to nursing home) for patients whose capacity to consent to a research study is formally assessed prior to obtaining consent compared with those whose capacity and consent are obtained in the usual combined way. No a priori power calculations were made.

\section{METHODS}

\section{Subjects and setting}

The study was conducted in the elderly care unit of a university hospital serving an inner city area, which admits patients over 65 years needing specialist assessment. The population studied here consisted of all patients 70 years or older admitted to the unit between November 2000 and January 2001 for acute assessment, directly from home via the accident and emergency department. Patients transferred from other admission wards in the hospital were included if this was within three days of admission to hospital. For patients admitted more than once during the study period only the first assessment was included.

\section{Study design}

Patients were approached within three days of admission to hospital having been randomly allocated to either a separate, formal test of capacity preceding consent (group A) or to an informal assessment in which the process of establishing capacity and obtaining consent were amalgamated according to usual research practice at the time (group B). The patients were randomised by list of numbers generated by a computer pseudorandom generator with clock seed.

\section{Procedures and measurements}

\section{Obtaining informed consent or assent}

Both groups were given the same amount of information (verbally and in writing). The formal capacity test is shown in 


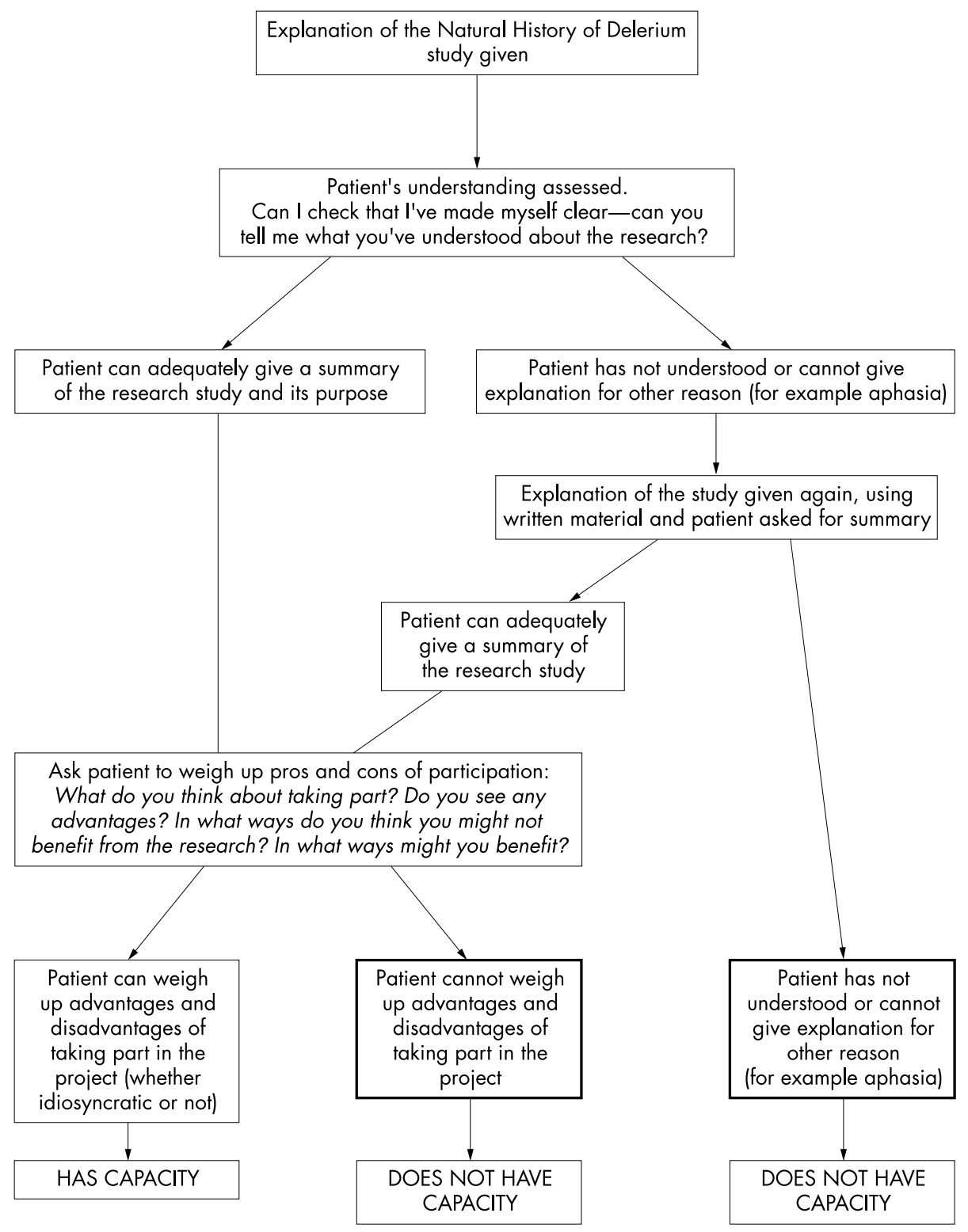

Figure 1 The procedure for formal assessment of capacity.

fig 1. Patients in group A who lacked capacity were not then asked for consent, but assent was sought from a proxy if available. The proxy was given the same information as the patient and they were asked to sign a statement to the effect that they neither opposed nor believed that the subject would be opposed to participation. In group B usual practice was followed, in which judgement was made of capacity while the project was explained, the information sheet shared, and consent sought; capacity and consent were somewhat intertwined. Assent from proxies for those who lacked capacity in group B was not obtained.

\section{Assessments}

All patients

The age, sex, discharge destination, and whether delirium was written or not written in the case notes was recorded for all patients. The length of hospital stay was recorded from the hospital information systems (PAS) and the outcome for each subject was classified as dead, discharged to same address, or discharged to a residential or nursing home.
Patients with capacity (judged by either method) who consented, or those without capacity but with relative assent

These patients were examined every $3( \pm 1)$ days until the 18th day of hospitalisation and again 10 days later, or earlier if they were to be discharged. The following assessments were made:

- Confusion Assessment Method $(\mathrm{CAM})^{29}$ for a dichotomous classification of delirium/not delirium

- Delirium Rating Scale (DRS) $)^{30}$ for an assessment of the severity of any delirium

- Mini-Mental Status Examination (MMSE) $)^{31}$ to assess cognitive impairment

- Reversible Cognitive Dysfunction Scale (RCDS $)^{12}$ to assess the presence of specific delirium clinical features shown to be associated with reversibility

- The Informant Questionnaire on Cognitive Decline in the Elderly (IQCODE) ${ }^{32}$ scale (16 items version ${ }^{33}$ ) to assess cognitive decline from preadmission or pre-illness by asking an informant by telephone or in person 
- APACHE II for measurement of severity of physical illness. ${ }^{34}$ Two measurements of APS (APACHE II subscale), arterial $\mathrm{pH}$ and oxygen saturation, were omitted to avoid withdrawal of arterial blood of patients. The Burden of Illness Score for Elderly Persons (BISEP) scale was also used as it predicts prognosis from illness in older patients (Inouye SK, Bogardus ST Jr, Vitagliano G, et al. The burden of illness score for elderly persons (BISEP): Cumulative impact of diseases, physiological abnormalities and functional impairments. Unpublished, used with the kind permission of the authors.)

- Katz scale for incident disability in activities of daily living $^{35}$

- Examination of the medical notes for investigation results, changes in diagnosis of medical condition, and current medication

\section{Analyses}

Data were analysed with SPSS (version 10). Two tailed parametric, or for non-normally distributed data non-parametric, tests were used as appropriate. Where Levene's test for inequality of variance was significant $(p<0.05)$, equal variances were not assumed in the $t$ test.

\section{Ethical procedure}

The original study protocol was approved by the Guy's and St Thomas' Research Ethics Committee. Subsequently, approval was also given to collect, anonymise, and report the basic clinical details and diagnostic data for all subjects approached, irrespective of their consent and assent. Consent or assent was recorded in writing. For all subjects, confidentiality was maintained by allocating subject numbers in place of names when data were aggregated and analysed.

\section{RESULTS}

Over $90 \%$ of all admissions to the unit were included in the study - the remainder being under 70 years or having already been in hospital for three days or more. The randomisation procedure divided the 130 patients approached into 57 in group A (43.8\%) and 73 in group B (56.2\%). No difference was found between groups A and B with regard to age, the percentage of men, length of hospital stay, or mortality (table 1). Fewer surviving patients in group A were eventually discharged to a nursing home than in group B but this was not statistically significant. There were 20 patients in each group for whom a diagnosis of delirium was recorded by clinical staff (case note delirium).

\section{Capacity and consent}

Figure 2 shows the results of the capacity assessments. Of the 57 subjects in group A $23(40.4 \%)$ failed the formal capacity test. Assent was obtained from relatives in only 3 $(13 \%)$ of these, 13 proxies being unavailable within the necessary timeframe and 7 unwilling. Of the 34 with capacity, $22(64.7 \%)$ consented to enter the study (Group ACC).

Of the 73 subjects in group B, $63(86.3 \%)$ had capacity, of whom 54 gave consent (group BCC), and 9 declined. Ten $(13.7 \%)$ were considered incapable of giving informed consent.

The method of assessment of capacity significantly affected the proportion of subjects finally entering the study. From group A, $25(43.9 \%)$ subjects entered the study versus $54(74 \%)$ from group B $\left(\chi^{2}=12.1, \mathrm{df}=1\right.$; $\mathrm{p}<0.001)$.

\section{Differences between those with capacity as assessed by the two methods - that is, prior to consent/assent (group AC v BC, see fig 2)}

Table 2 shows that there was no significant differences between the 34 subjects with capacity assessed by the formal method (group AC) and the 63 subjects with capacity judged informally (group BC) with regard to the proportion of men, those who had case note delirium, were discharged to a care home, or in length of hospital stay. There was a statistically significant difference in the proportions consenting to the study, and a trend towards being younger among those with capacity as assessed by the formal method compared with those assessed by the informal method.

\section{Differences between the two groups consenting to enter the study (group ACC v BCC, see fig 2)}

Table 2 shows that there were significant differences between those consenting to the study after a formal $(n=22)$ as opposed to an informal $(n=54)$ method of assessment of capacity. The former group was three years younger in mean age, scored four points higher (better) on initial MMSE, had lower initial RCDS scores and lower initial, final, and average DRS scores during the study. There was also a trend for them to have lower rates of initial CAM+ status. There was no difference with regard to sex or mortality between the groups but at discharge only one $(5 \%)$ of 20 survivors in the formally assessed group was discharged to a care home for the first time as opposed to 14 $(28.6 \%)$ of 49 survivors in the informally assessed group $\left(\chi^{2}=4.64, \mathrm{df}=1 ; \mathrm{p}=0.03\right)$.

With the addition of the three subjects with assent (AA), these differences remained as trends. The differences in the initial and average DRS remained statistically significant, and the difference in proportions entering care homes at discharge was greater $\left(\chi^{2}=5.26, \mathrm{df}=1 ; \mathrm{p}=0.022\right)$.

\begin{tabular}{|c|c|c|c|c|}
\hline & \multicolumn{2}{|c|}{$\begin{array}{l}\text { Method of assessment of } \\
\text { capacity }\end{array}$} & \multirow[b]{2}{*}{ Total } & \multirow[b]{2}{*}{$A v B$} \\
\hline & $\begin{array}{l}\text { Formal } \\
\text { (group A) }\end{array}$ & $\begin{array}{l}\text { Informal } \\
\text { (group B) }\end{array}$ & & \\
\hline No. of patients & 57 & 73 & 130 & \\
\hline Mean (SD) age, years & $83.4(6.1)$ & $83.8(6.8)$ & $83.6(6.5)$ & NS \\
\hline Men $(\%)$ & 47.4 & 41.1 & 43.8 & NS \\
\hline Case note diagnosis of delirium (\%) & 35.1 & 27.4 & 30.8 & $\chi^{2}=0.89 ; p=0.35$ \\
\hline Assessed as having capacity (\%) & 59.6 & 86.3 & & $\tilde{\chi}^{2}=12.00 ; p=0.001$ \\
\hline Mean (SD) length of stay, days & $21.4(20.7)$ & $20.0(16.4)$ & $20.6(18.3)$ & $\tilde{N} S$ \\
\hline Died in hospital (\%) & 15.8 & 15.1 & 15.5 & \\
\hline Survivors discharged to nursing home (\%) & 14.6 & 25.8 & 20.9 & $\chi^{2}=2.06 ; p=0.15$ \\
\hline
\end{tabular}




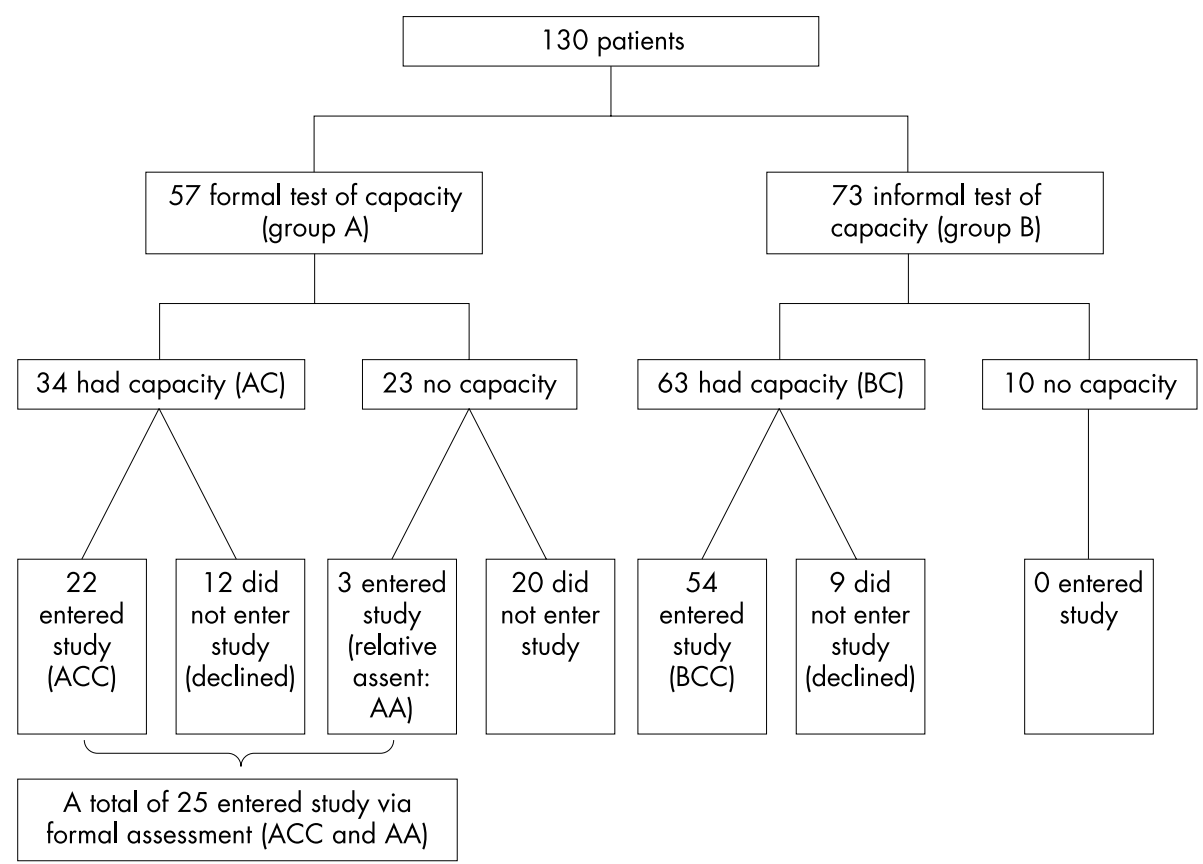

Figure 2 Derivation of the sample. Letters in parentheses refer to the groups compared in the analysis.

\section{Method of capacity assessment and case note diagnosis of delirium}

Of the 20 patients in each of the initial randomised groups (A and B) with case note delirium, 7 (35\%) in group A and 16 $(80 \%)$ in group $\mathrm{B}$ entered the study, $\left(\chi^{2}=8.29, \mathrm{df}=1\right.$; $\mathrm{p}=0.004)$.

\section{DISCUSSION}

This study suggests that implementing best ethical practice by a formal assessment of capacity to consent to a research project in an acute medical ward will lead to a considerable reduction in the proportion entering the study. Also, these data suggest that patients who enter a research study after a formal test of capacity may be unrepresentative of all patients who might enter a research study; in this instance they were younger, less cognitively impaired, and probably milder cases than those entering the study after an informal method of assessing capacity and gaining consent. The null hypothesis was not disproved except in the case of mortality and CAM scores, although the latter showed a trend to lower prevalence in those entering the study by the formal method.

A limitation of the study is that all assessments of capacity were performed by the same clinical researcher (DA), who was therefore not blinded to the group to which the subject was allocated when subsequently carrying out additional assessments of delirium and illness severity and when inspecting the clinical notes for evidence of the presence of delirium. Although a single researcher reduced the unreliability of ratings, systematic bias can only be controlled by a more rigorous and exhaustive study. Also, we used an indirect method to investigate case mix differences in terms of outcomes-these were secondary data. Given what is

Table 2 Characteristics of patients $(a)$ with and without capacity as assessed by the two methods $(A C v B C)$ and $(b)$ entering the study by the two methods ( $A C C \vee B C C$, three patients with relative assent excluded)

\begin{tabular}{|c|c|c|c|c|c|c|}
\hline & $A C$ & BC & $A C \vee B C$ & ACC & $\mathrm{BCC}$ & $\mathrm{ACC} v \mathrm{BCC}$ \\
\hline No. of patients & 34 & 63 & & 22 & 54 & \\
\hline Mean (SD) age, years & $81.6(6.1)$ & $84.2(6.8)$ & $\begin{array}{l}t=1.85, d f=95 \\
p=0.068\end{array}$ & $80.6(6.1)$ & $83.8(6.6)$ & $t=1.96, d f=74 ; p=0.053$ \\
\hline Men (\%) & 44.1 & 42.9 & NS & 40.9 & 44.4 & NS \\
\hline Case note diagnosis of delirium (\%) & 27.0 & 23.5 & NS & 22.7 & 29.6 & NS \\
\hline Mean (SD) length of stay, days & $20.6(19.0)$ & $18.9(16.1)$ & NS & $18.9(15.5)$ & $20.4(16.8)$ & NS \\
\hline Died in hospital (\%) & 8.8 & 9.5 & NS & 9.1 & 9.3 & NS \\
\hline Survivors discharged to nursing home (\%) & 18.8 & 22.2 & NS & 5 & 28.6 & $\chi^{2}=4.64, d f 1 p=0.03$ \\
\hline Declining to participate (\%) & 35.3 & 14.3 & $\chi^{2}=5.75 ; p=0.017$ & - & - & \\
\hline Mean initial MMSE (possible 30-0) & - & - & - & $21.0(6.2)$ & $16.7(8.6)$ & $\begin{array}{l}t=-2.46, d f=53 \\
p=0.017^{*}\end{array}$ \\
\hline Mean initial RCDS (possible 0-53) & - & - & - & $10.9(8.5)$ & $17.3(12.5)$ & $\begin{array}{l}t=2.54, d f=72.5 \\
p=0.014^{2}\end{array}$ \\
\hline Mean initial DRS (possible 0-32) & - & - & - & $4.4(3.4)$ & $7.8(7.3)$ & $\begin{array}{l}t=2.73, d f=72.5 \\
p=0.008^{2}\end{array}$ \\
\hline Mean final DRS & - & - & - & $3.6(4.2)$ & $6.7(7.3)$ & $\begin{array}{l}t=2.25, d f=64.8 \\
p=0.028^{2}\end{array}$ \\
\hline Mean DRS over all assessments & - & - & - & $4.0(3.2)$ & $7.3(6.8)$ & $\begin{array}{l}t=2.86, d f=72.1 \\
p=0.006^{2}\end{array}$ \\
\hline Initially CAM positive (\%) & - & - & - & 13.6 & 33.3 & $\chi^{2}=3.03 ; p=0.08$ \\
\hline
\end{tabular}

*Equal variances not assumed.

CAM, Confusion Assessment Method; DRS, Delirium Rating Scale; MMSE, Mini-Mental Status Examination; RCDS, Reversible Cognitive Dysfunction Scale. 
known about the recognition and recoding of delirium in case notes ${ }^{24}$ perhaps little weight can be placed on the differences in recording rates found in this study, but, anecdotally, these are high rates of recording delirium and it may be that in this unit these differences may reflect the tendency for a formal capacity test to differentially exclude patients with clear delirium.

In this empirical study of an ethical issue we encountered the vexing issue of whether it is acceptable to gather data about patients who either have no capacity to consent or decline to take part in the study. We found ourselves in a difficult position in prosecuting this strategy, albeit with full support of the local research ethics committee. If no data can be used without the expressed consent of competent patients, or the expressed assent of proxies if capacity is absent (or randomisation can only occur after consent), then exploration of the consequences of increased ethical rigour becomes impossible. We do not know just how and how much such strictures affect the case mix of patients recruited to a study. If we cannot say anything at all about the generalisability of a study, then it surely becomes, at best, ethically dubious, even if all procedures conform to the most meticulous standards. We conclude that the issue of how to assess capacity to consent to a research study should be contingent upon the likely harm to the patient on the one hand, and the potential harm done by non-generalisable and biased studies on the other.

The major significance of these findings is that distinct subsamples of subjects with delirium are likely to be recruited for studies according to the method of assessing capacity to give or withhold consent. Many potential participants do not have formal capacity to consent. In this study, including almost all prospective patients admitted to an elderly care unit, $40 \%$ lacked capacity to give consent to this research when judged by the standards epitomised in fig 1 . Since the majority of patients in an acute hospital who develop delirium have done so within a few days of admission, it is not feasible to seek prior prospective authorisation from these individuals. Inclusion by assent proved ineffective.

It may also be that the process of formal testing of capacity resulted in bias by inducing higher rates of declining to give consent. Two separate influences may have been at play. First, those with "formal" capacity were younger (81.6 years) than those with "informal" capacity ( 84.2 years, $p=0.068$ ), and secondly those who then consented were younger still (mean age 80.6 years). Thus the process of the formal assessment itself reduced the consent rate of older patients. This is credible, since it was a tiresome process for them. Although we have no observations of the cognitive status of those who declined and cannot be certain that the formal process differentially excluded more cognitively impaired or delirious subjects, assuming no difference in groups A and B at randomisation means that the differences in those entering the study indicate important selection bias, either through failure at the formal test of capacity or through refusal precipitated by the formal test, or both. Our results suggest that this bias is more likely to be at the consent stage rather than the capacity judgement stage. Although the differences in case note delirium and length of stay were not statistically significant, the direction of the differences is consistent: those subjects entered via the formal route (ACC and AA) had a lower incidence of delirium and left hospital sooner.

The consent rate may be greater if a stepwise approach to consent during participation is used. In this approach, called "experienced consent", verbal consent is accepted initially and, after the subject has experienced the project, written consent is sought. This has been shown to increase the capacity and willingness of prospective participants to give informed consent ${ }^{36}$ but does not solve the issue of capacity assessment. An alternative approach would be to recruit participants who lack capacity without assent but obtain consent later when, or if, capacity returns. Further work is necessary to identify an ethical approach that avoids selection bias in studies of acutely ill older patients with a high prior probability of having or developing delirium.

\section{SUMMARY}

As a preliminary part of a large scale study of delirium, we examined the issue of how best to obtain informed consent from older medical patients with delirium. We compared the results of a formal test of capacity using current legal guidelines with the usual informal method of assessing capacity and obtaining consent at the same time. We found that using the formal method excluded more patients overall, and also led to fewer people with case note delirium being recruited. Thus, a stringent assessment of capacity may lead to reduced generalisability of the study findings. In turn, this undermines the ethical justification of the study.

\section{Authors' affiliations}

D Adamis, Academic Unit, Ladywell House, London, UK F C Martin, Department of Ageing and Health, St Thomas' Hospital, London, UK

A Treloar, A J D Macdonald, Department of Old Age Psychiatry, Guy's, King's, and St Thomas' Schools of Medicine, Dentistry and Biomedical Sciences, London, UK

D Adamis was supported by the Bosher Memorial Bequest.

\section{REFERENCES}

1 Pompei $\mathbf{P}$, Foreman $M$, Rudberg MA, et al. Delirium in hospitalized older persons: outcomes and predictors. J Am Geriatr Soc 1994;42:809-15.

2 O'Keefe ST, Lavan JN. The prognostic significance of delirium in older hospital patients. J Am Geriatr Soc 1997; 45:174-8.

3 Inouye SK. The dilemma of delirium: clinical and research controversies regarding diagnosis and evaluation of delirium in hospitalized elderly medical patients. Am J Med 1994;97:278-88.

4 Inouye SK, Viscoli CM, Horwitz RI, et al. A predictive model for delirium in hospitalized elderly medical patients based on admission characteristics. Ann Intern Med 1993;119:474-81.

5 Inouye SK, Charpentier PA. Precipitating factors for delirium in hospitalized elderly persons. Predictive model and interrelationship with baseline vulnerability. JAMA 1996;275:852-7

6 Elie M, Cole MG, Primeau FJ, et al. Delirium risk factors in elderly hospitalized patients. J Gen Intern Med 1998;13:204-12.

7 Inouye SK, Rushing JT, Foreman MD, et al. Does delirium contribute to poor hospital outcome? A three site epidemiological study. J Gen Intern Med 1998; 13:234-42.

8 Levkoff SE, Evans DA, Liptzin B, et al. The occurrence and persistence of symptoms among elderly hospitalised patients. Arch Intern Med 1992;152:334-40.

9 Francis J, Kapoor WN. Prognosis after hospital discharge of older medical patients with delirium. J Am Geriatr Soc 1992:40:601-6.

10 Inouye SK, Bogardus ST Jr, Charpentier PA, et al. A multicomponent intervention to prevent delirium in hospitalized older patients. N Engl J Med 1999;340:669-76.

11 Britton A, Russell R. Multidisciplinary team interventions for delirium in patients with chronic cognitive impairment (Cochrane Review). In:Cochrane Library, Issue 4. Oxford: Update Software, 2000.

12 Treloar AJ, Macdonald AJD. Outcome of delirium: 2. Clinical features of reversible cognitive dysfunction - are they the same as accepted definitions of delirium? Int J Geriatr Psychiatry 1997; 12:614-18.

13 Macdonald AJ, Treloar A. Delirium and dementia; are they distinct? J Am Geriatr Soc 1997;44:1001-2.

14 Koponen HJ. Neurochemistry and delirium. Dement Geriatr Cogn Disord 1999; 10:339-41.

15 Treloar A, Macdonald A. Outcome of delirium: Part 1. Outcome of delirium diagnosed by DSM-III-R, ICD-10 and CAMDEX and derivation of the Reversible Cognitive Dysfunction Scale among acute geriatric inpatients. Int J Geriatr Psychiatry 1997;12:609-13.

16 Bugeja G, Kumar A, Banerjee AK. Exclusion of elderly people from clinical research: a descriptive study of published reports. BMJ 1997;315:1059.

17 British Medical Association and The Law Society. Assessment of Mental Capacity. Guidance for Doctors and Lawyers. London: BMA, 1995.

18 Department of Health. Reference Guide for Consent for Examination or Treatment. London: The Stationery Office, 2001.

19 Medical Research Council. The Ethical Conduct of Research on the Mentally Incapacitated. London: Medical Research Council, 1993. 
20 Mukheriee S, Shah A. Capacity to consent: issues and controversies. Hosp Med $2001 ; 62: 351-4$.

21 Appelbaum PS. Rethinking the conduct of psychiatric research. Arch Gen Psychiatry 1997; 54:117-20.

22 Fitten LJ, Waite MS. Impact of medical hospitalization on treatment decisionmaking capacity in the elderly. Arch Intern Med 1990;150:1717-21.

23 Auerswald KB, Charpentier PA, Inouye SK. The informed consent process in older patients who developed delirium: a clinical epidemiologic study. Am J Med 1997; 103:410-18.

24 Inouye SK. Delirium in hospitalized older patients: recognition and risk factors. J Geriatr Psychiatry Neurol 1998;11:118-25.

25 Levkoff SE, Safran C, Cleary PD, et al. Identification of factors associated with the diagnosis of delirium in elderly hospitalized patients. J Am Geriatr Soc 1988;36:1099-104.

26 World Medical Association Declaration of Helsinki. Ethical Principles for Medical Research Involving Human Subjects. as amended by the 52nd WMA General Assembly, Edinburgh: October, 2000.

27 Capron AM. Ethical and human rights issues in research on mental disorders that might affect decision making capacity. N Engl J Med 1999:340:1430-4.

28 Marcantonio ER, Flacker JM, Wright RJ, et al. Reducing delirium after hip fracture: a randomised trial. J Am Geriatr Soc 2001;49:516-22.
29 Inouye SK, van Dyck CH, Alessi CA, et al Clarifying confusion: The Confusion Assessment method. Ann Intern Med 1990;113:941-8.

30 Trzepacz PT, Dew MA. Further analyses of the Delirium Rating Scale. Gen Hosp Psychiatry 1995; 17:75-9.

31 Folstein MF, Folstein SE, Mc Hugh PR. Mini-mental state: a practical method for grading the cognitive state for the clinician. J Psychiatr Res 1975; 12:189-98.

32 Jorm AF, Jacobs PA. The Informant Questionnaire on Cognitive Decline in the Elderly (IQCODE): socio-demographic correlates, reliability, validity and some norms. Psychol Med 1989;19:1015-22.

33 Jorm AF. A short form of the Informant Questionnaire on Cognitive Decline in the Elderly (IQCODE): development and cross-validation. Psychol Med 1994;24:145-53.

34 Knaus WA, Drapes EA, Wagnes DP, et al. APACHE II: a severity of disease classification system. Crit Care Med 1985;13:818-29.

35 Katz S, Downs TD, Cash HR, et al. Progress in development of the index of ADL. Gerontologist 1970;10:20-30.

36 Olde Rikkert MGM, van den Bercken JHL, ten Have HAMJ, et al. Experienced consent in geriatrics research: a new method to optimise the capacity to consent in frail elderly subjects. J Med Ethics 1997;23:271-6.

\section{Register now!}

10th European Forum on Quality Improvement in Health Care

13-15 April 2005, ExCel Conference Centre, London

For further information on how to register please go to:

http://www.quality.bmjpg.com 